\title{
Pursuing the Energetic yet Enigmatic Particle that Powers English Communication
}

\author{
Dennis Michael Bryant (Corresponding author) \\ Faculty of Arts, University of Canberra \\ 11 Kirinari Street, BRUCE, Australian Capital Territory, CANBERRA, 2617, Australia
}

Tel: 61-04-0049-9265Ｅmail: DrDennisBryant@gmail.com

Received: August 5, 2020 Accepted: October 15, 2020 Published: October 18, 2020

doi:10.5296/ijch.v7i2.17488 URL: https://doi.org/10.5296/ijch.v7i2.17488

\begin{abstract}
English is determined to use words in multiple scenarios and her determination extends, unmistakeably, to one energetic preposition particle. However, an irony exists here because prepositions are generally rather small words, and easily overlooked by speakers and grammars. Indeed the particle under discussion is merely a two-letter word, but its usage must be described as phenomenal. This paper claims that this particle easily outstrips its preposition peers in aptitude, a talent that can be demonstrated by cataloguing its numerous placements. Apart from demonstrating a plethora of placements, this paper offers a single, yet innovative grammatical definition to cover the particle's usage. In this regard, this paper advances the OF-insertion hypothesis. The methodology herein is to employ exemplar sentences to demonstrate the particle's roles. Such a technique has proven its validity in recently published papers on English Grammar. It is true of course that such a particle did not appear out of the blue, hence some exemplars are necessary to demonstrate its growth over grammatical time. Beneficiaries of this paper's findings will be English as a Second Language teachers, in that they will have a comprehensive endowment from which to teach which, it is hoped, will empower their ESL students' progress towards full fluency.
\end{abstract}

Keywords: ESL educational practice, ESL curriculum redevelopment, ESL teaching, Second language acquisition

\section{Introduction}

Today's speakers may not be consciously aware that 'of' described herein as a particle, services their communications in a host of situations. It is not hyperbole to use a term such as 'host'. A quick consultation with a dictionary shows that sixteen distinctions are given to the 
'of' particle, and this high number is suggestive of an energetic particle. Indeed, the plot thickens because almost all sixteen distinctions have sub-distinctions, and this equates to thirty distinctions in total. Reflecting on this large number, some questions arise. For example, did English language - from fifth century Old English (sometimes referred to as Anglo-Saxon English, or simply OE); until Chaucer's fourteenth century Middle English (ME); until today's twenty-first century Modern English (MnE) - always have so many distinctions; or has there been growth over time, and what are the distinctions today? An associated question arises with regard to whether ESL student acquisition of the particle is likely to succeed given a high number of distinctions? This question is framed against a suspicion that ESL textbooks have not catered well for ESL students, historically. In fact, have grammarians been aware of a host of distinctions? Although anecdotal, when native speakers are asked to outline 'of" distinctions, they are incredulous that such a request is warranted for such a non-descript particle. In fact, blank native speaker responses may infer that the particle is an enigma in being highly used yet taken for granted. Of course, there is no doubt that native speakers mastered this particle, but unlike ESL speakers, native speakers have had ample amounts of time to achieve their self-automatization.

This paper believes that there has been a growth in the grammatical use of the 'of' particle. However, at the same time, there is a suspicion that thirty distinctions in total is unintended hyperbole and not likely to be sustained under investigation. Therefore, this paper acknowledges that producing a much-shortened set of distinctions is achievable, by collapsing together those distinctions categories that appear to overlap or else, specify a single definition. Although Professors of Semantics may quibble, this is a realistic step. It is realistic because native speakers managed complete automatization at a childish age, and this paper feels that it is realistic to propose that such usage perfection was likely to have succeeded widely given that a narrower range of valid distinctions were detected.

\section{Literature Review}

The 'of' particle has existed in English for a long time, and examples of its usage can be witnessed as far back as $\mathrm{OE}$, through to ME, and into today's MnE. For example, Gunn \& Eagleson refer to the 'of' particle as a 'partitive genitive' when translating part of the OE Anglo-Saxon Chronicle, but when discussing the particle in MnE, Gunn \& Eagleson do so in terms of a stylist choice available to a speaker. If the Gunn \& Eagleson approach seems minimalistic, A. G. Mitchell's approach is ultra-minimalistic, finding no room at all for discussion in his chapter on grammar. In succeeding times, Bolinger found the 'of' particle needs no individual definition because, in his view, it could be lumped together with 'the, which, my, when, and, if...', as fellow function words which could be co-aligned to form compound prepositions. However, Bolinger's grouping of disparate words might be viewed as arbitrary and therefore convenient, rather than being creditable. Langacker, a linguist similar to Bolinger in vintage, takes an approach that seems more minimalistic in that his discussion limits itself to an 'of' deletion rule, which seems to be unwarranted since the 'rule' is known by native speakers and he is not writing for an ESL audience. In contrast, Bruce Mitchell sees the main role for the 'of' particle as prepositional. 
Recapping, these examples signal a willingness to ignore the 'of' particle; or else a willingness to camouflage it inside a group of words, somewhat randomly chosen. However, that camouflage tendency still persists today in as much as the particle is seen commonly as belonging to the 'preposition' grouping. See for example, Simpson; Downing \& Locke; Kittredge \& Farley. Further perpetuating a lack of clarity, the Macquarie Dictionary lists sixteen definitions for the particle. Taking the first entry as an example, it reads 'Distance or direction from, separation, deprivation, riddance, etc.: within a metre of; to cure of'. Given that there are fifteen further sections, each containing several supposedly definitive statements, it seems reasonable to conclude that these examples may be well-meaning but are otherwise unlikely to edify ESL students' demand for a comprehensible statement on the particle. This paper suggests that the rise in 'of' usage was not a quaint semantic or grammatical occurrence; but its rise was accelerated by the need to separate nouns from each other, given a decline in the usage of case endings on nouns in OE. While 'of' usage began in $\mathrm{OE}$, its growth in usage become more evident in $\mathrm{ME}$ and in $\mathrm{MnE}$ as almost every case ending was discarded. At this point, a question must be put: were grammarians incorrect, as this paper suggests, in assigning the 'of' particle into a wide-ranging preposition grouping, thereby hiding its uniqueness?

Perhaps an approach to answering this question can be found in Critical Thinking theory, where Hamby notes that the cardinal critical thinking virtue is a willingness to inquire. Elaborating further, Hamby clearly states that possession by an analyst of a single cardinal virtue, however admirable, is not sufficient to guarantee success. He makes the point that the virtue must be accompanied by an appropriate skill-set of "reasoned judgement". On this point, perhaps Vardi's summary is more informative in stating that a key principle is being 'methodical', and a key action is to 'follow the trail of evidence'. The Hamby and Vardi viewpoints infer that random assignment would constitute an absence of Critical Thinking virtues, such as reasoned and methodical judgement, and this means that although the 'of' particle has longevity, it is yet to be adequately treated in today's grammatical textbooks.

In order to follow the trail of evidence, this paper suggests that there is an outstanding need to analyse 'of' particle usage with a view to determining at least two explanatory outcomes, from which the superior outcome could be selected. An inferior outcome would be to characterise ' $o f$ " particle usage as falling into multiple categories. A superior outcome would be to characterise ' $o f$ ' particle usage as constituting a single grammatical role, especially a role that has persisted from $\mathrm{OE}$ to $\mathrm{ME}$ to MnE times. Belief in achieving the latter outcome is not far-fetched because native speakers have subconsciously recognised a superior category during their language automatization, giving them native speaker speed and correctness of communication when using this enigmatic yet energetic particle.

To address this claimed grammarian blind spot, this paper offers the $O F$-insertion hypothesis as the missing link. The OF-insertion hypothesis is rooted in this paper's reflection on historical change implications in which noun endings were discarded, leaving a need to clarify their roles. Apart from its early beginnings, OF-insertion has flourished over time and it can be defined as a method to associate two (or more) nouns, the first of which is not functioning as an adjective modifying a later noun. OF-insertion extends English 
expressibility in that it enables a simple chaining together of noun concepts, and while the semantic outcomes can be complex, the effort is minimal.

Part of the motivation for this paper is a belief that an innovative discernment, such as the OF-insertion hypothesis, represents a fresh approach which could be congruous with empowering student learning autonomy, as espoused by Benson; as well as being congruous with student motivation; with student strategies; and with student intelligence. In terms of Teaching and Learning theory, but also constituting a small part of the rationale for this paper, it is hoped that an integrated overview of the particle will function to assist each ESL learner to form, according to Bruner's theory of scaffolding, essentially a coat-hanger in the mind upon which a silhouette of English can be formed and then be built into a corpus of applicable knowledge.

Although this paper's intention is to fete the innovative OF-insertion hypothesis and its relevance to pedagogy, it remains to mention a peer of the 'of' particle; namely, the Apostrophe-S method of associating nouns. The Apostrophe-S method is described as a peer to the 'of' particle for historical and functional reasons: both were available in OE; both travelled from $\mathrm{ME}$ through to $\mathrm{MnE}$; and both can produce similar outcomes. But like peers, their similarity does not guarantee their identicality. The Apostrophe-S method differs in that it converts a noun into an adjective whose function is to modify a following noun. However, the similarity is that Apostrophe-S usage does associate concepts, given that it converts former nouns into adjectives and then stacks them in front of an unconverted noun.

\section{Methodology}

This paper's approach to describing the 'of' particle is done through an organized presentation of, and discussion of, exemplar sentences. These exemplar sentences are organized into sections based on language type, beginning with $\mathrm{OE}$, then ME. To assist readers, each exemplar is accompanied by MnE equivalents. In respect of ME, exemplars are taken from a work entitled 'The Caunterbury Tales of Geoffrey Chaucer'. Although some of the ME exemplars show differences to $\mathrm{MnE}$, readers may be pleasantly surprised at the similarities that also occur, and this similarity is evidenced by Chaucer's easily decipherable title. Additionally, readers may be edified to find continuums of usage.

This paper's approach of analytical re-measurement is not out of place, because it emulates the approach taken in recently published papers, these being the innovative Focus-Promotion premise which concerned altering word prominence in pursuit of grammatical convenience; in focussing on verb structure mastery for ESL speakers; in focusing on decoding contractions, again for ESL speakers; in focussing on the form and function that defines and associates Articles. Those publications have shed new light on the hidden-in-plain-sight features and operations of English, and hopefully this paper will serve to inform ESL teachers, in an equivalently useful manner.

\section{Findings}

Below are three sections, unequal in size, but nevertheless containing a number of exemplar samples, whose purpose is to demonstrate the uses undertaken over time by the energetic 'of' 
particle. It is hoped that these sample sentences, and their accompanying commentaries, will conspire to remove the enigmatic veil that seems to have lain upon grammarians for so long with regard to this particle.

\subsection{Old English Examples}

The following OE example is taken from Bruce Mitchell.

àn of èow twelfum - meaning 'one of you twelve'.

It is noticeable that the OE form of 'twelfum' is longer than 'twelve' as in today's language. This is because a '-um' case-ending was suffixed to 'twelf' as a then-accepted grammatical way of indicating ' $o f$ '. Given the presence of the free-form ' $o f$ ' earlier in the utterance, this may seem to be a strange situation. However, the two equivalents can be taken to show that OE was undergoing change. It was destined to lose almost every case-ending, yet retain 'of'. In fact, Wrenn calls this period of transition from OE to ME 'the period of lost inflections' where Wrenn's use of the term 'inflections' is equivalent to 'case-endings'. Therefore, a more literal translation of the phrase, showing both a free-form and a bound-form, could be 'one of you twelve-of'. Gunn \& Eagleson provide similar examples and explanations of the OE particle, taken from the twelfth century 'Anglo-Saxon Chronicle'.

\subsection{Middle English Examples}

As 'of' usage grew, it is not surprising to find its inclusion in a classical poem, notably entitled 'The Caunterbury Tales of Geoffrey Chaucer'. Following are the first five lines of verse from Chaucer's poem describing a group pilgrimage to the shrine of the martyr, St. Thomas Becket at Canterbury. The verses follow.

'Here Bygynneth the Book of the Tales of Caunterbury. / Whan that Aprill with his shoures soote (sweet showers)

The droghte of March hath perced (pierced) to the roote, I And bathed every veyne (vain) in swich licour (that liquid),

Of which vertu (the power of which) engendred (produced) is the flour (flower)'.

The great Poet of ME times is Shakespeare and it would be remiss to not reference his 'of' particle usage. The first two lines of The Tragedy of Richard the Third play, as spoken by Richard of Gloucester, begins thus:

'Now is the winter of our discontent / made glorious summer by this sun of York'

\subsection{Modern English Examples}

The following example stays with a theme that depicts 'of' particle usage in poetry, but switches to MnE with the intention of considering the ode To Autumn by Keats.

'Season of mists and mellow fruitfulness, / Close-bosom friend of the maturing sun;

Conspiring with him how to load and bless / With fruit the vines that round the thatch-eves run;' 
In the example above, Keats maintains a looping cadence in describing a twisting vine. Of relevance here is Keats' close juxtaposition of two nouns, both of which are underlined. At first sight, the juxtaposition of nouns appears to breach the $O F$-insertion hypothesis, which specifies a requirement for 'of' particle insertion to occur between two nouns, neither of which is deemed to be acting as an adjectival modifier. Remembering of course that language commentary must always respect a communicator's aim, Keats' poem intentionally breaches the OF-insertion hypothesis because he grants himself a degree of poetic licence in order to promote cadence of expression over all other considerations.

Turning away from the joy of poetry to an emphasis on simple prose, so as not to infer that the major use of the particle is poetry, here is a complementary example. Although the following exemplar contains no hint of rhythm such as there is in poetry, the particle serves to deliver a depth of images that are striking to the point that the particle seems to disappear even though it is the cement helping to create those images.

The deadly outcomes of the fires of 2019 were a reminder of the terrible power of Nature's wrath. The avoidance of a complete disaster was only possible due to the rapid detection of dry lightening strikes and thus an inevitable development of multiple outbreaks of fire in the pristine forests of cedar, of sycamore and of gum trees that surround farming land. The immediate intervention of self-appointed volunteer fire-fighters did stem the number of outbreaks of fires. However, all of 'the King's horses and all of the King's men couldn't put' the thousands of acres of flora, nor the multitude of fauna back together again' (an intentional misquote of the Humpty Dumpty rhyme). It was remiss of farmers to be dreaming of the greening of their crops in their paddocks when there was evidence of the likelihood of the approach of demonic fires. Additionally, weather reports of droughts and of flooding rains might benefit from the inclusion of text, such as, 'and of demonic fire-fronts'.

There is, of course, a peer to the OF-insertion method and this is the Apostrophe-S method. In the latter method, a stacking of nouns is achieved by inflecting a cluster of all-but-one noun into adjectives by the inclusion of a bound-form, namely Apostrophe-S. Today's Apostrophe-S was evident in ME where it was often written as 'es', but has normalised to Apostrophe-S, possibly helped by the widespread popularity of Shakespeare. Consider the following MnE example.

We travelled in Anne's sister's friend's car to see Shakespeare's Love's Labor's Lost play.

Although it is valid to regard Apostrophe-S and OF-insertion as peers, speakers have preference in their use, and while this preference may be driven by multiple determinants, speed of communication may be a determinant. To demonstrate preference, consider the example below which is an attempt at converting the previous Apostrophe-S example into OF-insertion usage.

We travelled in the car of a friend of the sister of Anne to see the Loss of the Labor of a Love play of Shakespeare. 
Shown below is this paper's final exemplar sentence. Readers may wish to transform this OF-insertion into an Apostrophe-S inflection exemplar. Although it may be technically possible to succeed in a transformation, the challenge was essentially rhetorical, but it is one final chance for this paper to make the point that $O F$-insertion is a simple and elegant way to chain together multiple noun images in English.

The irony of the situation of stacking boxes of vials of Corona Virus vaccine injections was that not a single one of our team of doctors anticipated an eruption of the nearby volcano.

As this paper approaches closure in its disclosure about the exuberant role taken up by the 'of' particle, one question remains: is the 'of' particle more relevant than other prepositions - after all, according to Kittredge \& Farley, there are around one hundred and seventy prepositions? In measuring word frequency, the British National Corpus notes that the 'of' particle is second only to the definite article in usage, as reported by Cook, and thus ahead of all other prepositions in usage; and this dominant frequency of usage seems to justify its selection for analysis.

\section{Limitations}

Apart from reporting 'of' to be prepositional in OE usage, Mitchell also reports it has an adverbial use in OE, meaning 'off, away'. However, while his observation might prove true for $\mathrm{MnE}$, this paper took the approach that the innovative OF-insertion hypothesis, as discussed herein, is likely to be of wider relevance to today's ESL pedagogy.

\section{Conclusion}

This paper concerned itself with the 'of' particle which has traditionally been mis-pooled with prepositions, being considered as a nondescript two-letter word and not deserving of an analysis which could portray its unique grammatical characteristics and its fundamental difference to prepositions. Yet, a willingness to enquire, by following 'the trail of evidence' as recommended by Critical Thinking theory, has shown that the 'of' particle is used energetically in English communication, in spite of the irony that the particle is a mere two-letter word. This particle's exuberance has been demonstrated in its numerous placements. Those placements show that the 'of' particle facilitates the chaining together of multiple noun concepts, thereby servicing a notable increase in English expressibility with no discernible change in construction cost. Even though it may read as hyperbole, it seems to be true that English communication has benefitted from growth in the use of the particle to convey simply-constructed yet vivid imagery. To describe formally the particle's efficient method of chaining together with nouns to produce imagery, in both poetry and prose, this paper proposed the OF-insertion hypothesis. Exemplar sentences demonstrated instances featuring particle usage. It is true of course that such a particle did not appear out of the blue, hence exemplars were also provided to demonstrate its growth over grammatical time; this being from ninth century Old English, to fourteenth century Middle English, through to today's Modern English. Beneficiaries of this paper's findings will be English as a Second 
Language teachers, in that they now have a comprehensive endowment from which to teach; thereby, it is hoped, empowering their ESL students' progress towards full fluency.

\section{References}

Benson, P. (2001). Teaching and researching autonomy in language learning. New York: Longman.

Bolinger, D. (1968). Aspects of Language. New York: Harcourt, Brace \& World, Inc.

Briggs, E. (1967). Complete Poetry and Selected Prose of Keats. New York: Random House, Inc.

Bruner, J. (1978). The role of dialogue in language acquisition. In A. Sinclair, R., J. Jarvelle, \& W. J. M. Levelt (Eds.), The Child's Concept of Language. New York: Springer-Verlag.

Bryant, D. M. (2019a). Focussing on Promotion in English Sentences to inform ESL Educational Practice, Language, Literature and Culture, 2(3), 108-113. [Online] Available: http://www.aascit.org/journal/archive?journalId=932

Bryant, D. M. (2019b). Focussing on Building up ESL Perception of Verb Slot Complexity to inform Educational Practice. Language, Literature and Culture, 2(3), 133-138. [Online] Available: http://www.aascit.org/journal/archive?journalId=932

Bryant, D. M. (2019c). Focussing on Decoding Contractions in English Sentences to Inform ESL Educational Practice. International Journal of Culture and History, 6(2), 90-101. https://doi.org/10.5296/ijch.v6i2.15892

Bryant, D. M. (2020). The Form and the Function that Defines and Associates Definite and Indefinite Articles in English Grammar. International Journal of Culture and History, 7(1), 30-40. https://doi.org/10.5296/ijch.v7i1.17213

Christison, M. A. (2002). Multiple intelligences and language learning: A guidebook of theory, activities, inventories, and resources. Burlingame, CA: Alta Book Center.

Cohen, A. D. (1998). Strategies in learning and using a second language. New York: Longman.

Cook, D. (1961). The Canterbury Tales of Geoffrey Chaucer. New York: Anchor Books.

Cook, V. (2016). Second Language Learning and Teaching. (5th ed.). London: Routledge. https://doi.org/10.4324/9781315883113

Dornyei, Z. (2001). Teaching and researching motivation. New York: Longman. https://doi.org/10.1075/hop.5.mot1

Downing, A., \& Locke, P. (2006). English Grammar: A university course. London: Routledge. https://doi.org/10.4324/9780203087640

Eccles, M. (1964). Richard III. New York: The New American Library Inc.

Gunn, J. S., \& Eagleson, R. D. (1966). Survey of Language. Sydney: Angus \& Robertson. 


\section{Macrothink}

Hamby, B. (2015). Willingness to Inquire: The Cardinal Critical Thinking Virtue. In M. Davies, \& R. Barnett (Eds.), The Palgrave Handbook of Critical Thinking in Higher Education (pp. 77-88). New York: Palgrave MacMillan. https://doi.org/10.1057/9781137378057_5

Kittredge, G. L., \& Farley, F. E. (2014). An Advanced English Grammar with Exercises. New York: Franklin Classics Trade Press.

Langacker, R. W. (1973). Language and its Structure: some fundamental linguistic concepts. (2nd ed.). New York: Harcourt Brace Jovanovic, Inc.

Mitchell, A. G. (1962). The Use of English. Sydney: Angus \& Robertson.

Mitchell, B. (1995). An Invitation to Old English and Anglo-Saxon England. (3rd ed.). Oxford: Blackwell Publishers Ltd.

Simpson, R. (2003). English Grammar: Teach Yourself series. (2nd ed.). New York: McGraw-Hill.

The Macquarie Dictionary. (2005). Sydney, Australia: The Macquarie Library Pty. Ltd.

Vardi, I. (2015). The relationship between Self-Regulation, Personal Epistimology, and Becoming a "Critical Thinker": Implications for Pedagogy. In M. Davies, \& R. Barnett (Eds.), The Palgrave Handbook of Critical Thinking in Higher Education (pp. 197-212). New York: Palgrave MacMillan. https://doi.org/10.1057/9781137378057_13

Wrenn, C. L. (1949). The English Language. London: Methuen \& Co. Ltd.

\section{Copyright Disclaimer}

Copyright reserved by the author(s).

This article is an open-access article distributed under the terms and conditions of the Creative Commons Attribution license (http://creativecommons.org/licenses/by/3.0/). 